\title{
Opportunistic feeding by the fungiid coral Fungia scruposa on the moon jellyfish Aurelia aurita
}

Received: 2 April 2009/Accepted: 4 May 2009/Published online: 21 May 2009

(C) Springer-Verlag 2009

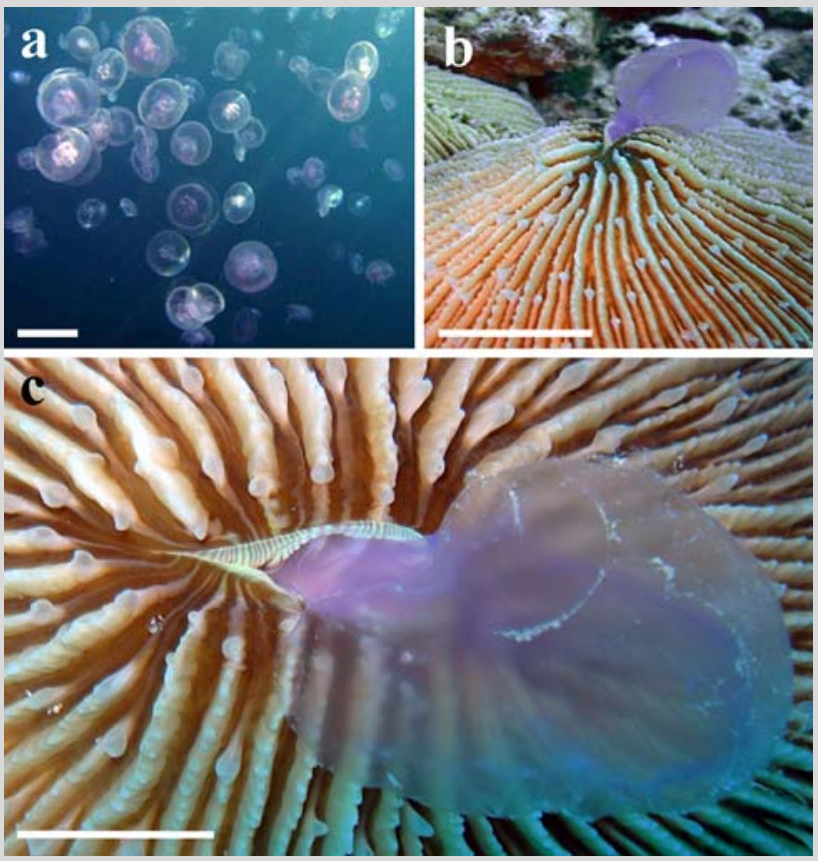

Fig. 1 a Aurelia aurita bloom in the Gulf of Aqaba (March 2009). Scale bar $=10 \mathrm{~cm}$; b Lateral view of the coral Fungia scruposa feeding on A. aurita Scale bar $=5 \mathrm{~cm}$; c Close up of $F$. scruposa swallowing the jellyfish. Scale bar $=2 \mathrm{~cm}$
The Gulf of Aqaba (Red Sea) is characterized by seasonal plankton blooms which are driven by vertical nutrient

upwelling during winter (Genin et al. 1995). In March 2009, following the seasonal upwelling, large numbers of the moon jellyfish (Aurelia aurita) were recorded at the local fringing reefs of Eilat, at depths of 2-20 m (Fig. 1a). During this event, several large (ca. 20-25 cm) solitary corals (Fungia scruposa) were observed to feed on these jellyfish (Fig. 1b, c).

A. aurita is known to be eaten by a wide variety of relatively large predators, including fish, sea turtles and even sea birds; however, it has never been reported as a coral's prey. Despite the fact that hermatypic corals may feed heterotrophically on a broad variety of sources ranging in size from bacteria to mesozooplankton (up to $1,000 \mu \mathrm{m}$ ) (Houlbrèque and Ferrier-Pagès 2009), this is the first report of solitary corals feeding on large gelatinous plankton (ca. $12 \mathrm{~cm}$ in diameter) in their natural habitat. Other cnidarians, such as the sea anemone Entacmaea medusivora in Palau, have also been shown to feed on jellyfish (Mastigias papua). However, as opposed to F. scruposa, these sea anemones are constantly surrounded by their prey and they lack photosynthetic endosymbionts (Fautin and Fitt 1991). Our observations revealed that the large-mouthed solitary fungiids can consume relatively large prey organisms, which are not available to other corals, as an additional source of protein. It remains to be shown, however, how fungiid corals manage to capture these large jellyfish while overcoming their motility. This trophic opportunism and reproductive plasticity exhibited by fungiid corals (Loya and Sakai 2008) are suggested as an important asset in determining their evolutionary success.

\section{References}

Fautin DG, Fitt WK (1991) A jellyfish-eating sea anemone (Cnidaria, Actiniaria) from Palau: Entacmaea medusivora sp. nov. Hydrobiologia 216-217:453-461

Genin A, Lazar B, Brenner S (1995) Vertical mixing and coral death in the Red Sea following the eruption of Mount Pinatubo. Nature 377:507-510

Houlbrèque F, Ferrier-Pagès C (2009) Heterotrophy in tropical scleractinian corals. Biol Rev 84:1-17

Loya Y, Sakai K (2008) Bidirectional sex change in mushroom stony corals. Proc R Soc B 275:2335-2343

\section{A. Alamaru $(\bowtie) \cdot$ O. Bronstein · Y. Loya}

Department of Zoology, George S. Wise Faculty of Life Sciences, Tel Aviv University, 69978 Tel Aviv, Israel e-mail: alamarua@gmail.com

G. Dishon

Mina and Everard Faculty of Life Sciences, Bar Ilan University, 52900 Ramat Gan, Israel

G. Dishon

Interuniversity Institute for Marine Science, P. O. Box 469, 88103 Eilat, Israel

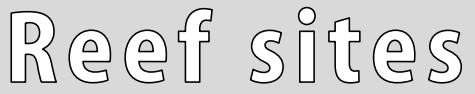

Coral Reefs (2009) 28:865 DOI $10.1007 / \mathrm{s} 00338-009-0507-7$ 